\title{
NOTAS A DIEZ POEMAS DE GUERRA DE ANTONIO MACHADO
}

AMELIA DE PAZ

Para Pablo Luis Ávila

\section{RESUMEN}

Principales datos que pueden establecerse con respecto a la edición de la poesía escrita por Antonio Machado en su etapa final: fechas de composición, circunstancias biográficas, errores de transmisión, fijación textual a partir de los autógrafos.

Palabras claves: Antonio Machado. Poesía de la guerra civil española. Crítica textual.

\section{ABSTRACT}

Main possible data concerning the editing of Antonio Machado's last poems: dates of composition, biographical context, mistakes in further editions, reconstruction according to autographs.

Key words: Antonio Machado. Spanish Civil War's poetry. Textual criticism.

Se trata de las coplas «Papagayo verde» y «Sobre la maleza», los cuatro sonetos «escritos una noche de bombardeo, en Rocafort (Valencia)[,] Marzo de 1938» («Más fuerte que la guerra —espanto y grima—», « $Y$ Ya su perfil zancudo en el regato...!», «Estas rachas de marzo, en los desvanes», «Otra vez en la noche... Es el martillo»), y los de la serie La guerra («De mar a mar entre los dos la guerra», «Otra vez el ayer. Tras la persiana», «Trazó una odiosa mano, España mía», «Mas tú, varona fuerte, madre santa»). Todos ellos se gestaron y publicaron en circunstancias bien penosas, sobre las que supo alzarse la maestría de Antonio Machado para evitar los dos escollos que acechan a un poeta en tiempos de guerra: la verborrea y el mutismo. Aquellas explican seguramente también, en parte, la precariedad textual de tan hermosos poemas, objeto de estas páginas.

Los diez se dieron a conocer en una publicación dirigida por Juan José Domenchina, a quien la guerra civil española había aproximado física y espiritualmente a don Antonio: el Servicio Español de Información, Textos y Documentos, órgano de la Subsecretaría de Propaganda del gobierno re- 
publicano. Domenchina desempeñó su jefatura desde abril de 1937, primero en Valencia y, a partir del 17 de noviembre de ese año, en Barcelona. El Servicio Español de Información, boletín diario no venal de cuatro páginas, ejercía la propaganda sin escatimar esfuerzos y sin incurrir en el estilo panfletario — cualidades raras las dos-, aderezando ocasionalmente la crónica bélica o política con el ingrediente poético, tan eficaz. Que «no hay guerra sin retórica» —en expresión de Mairena ${ }^{1}$ — es sabido por todo el que se haya asomado a la prensa del momento, como también lo es que el nombre de Antonio Machado, oráculo para uno de los bandos, no falta en ninguna publicación que se precie de republicanismo militante. La Subsecretaría de Propaganda no iba a ser precisamente la excepción: en una etapa de trabajo agotador en que es requerido sin descanso, Machado, lector habitual del Servicio, es al tiempo una de sus firmas más ilustres. No solo en prosa: cierta confidencia de Domenchina revela que en su primer suplemento literario, que no hemos logrado localizar, se imprimieron las Coplas mencionadas $^{2}$. En otro de tales suplementos salieron los sonetos; de este último sí nos consta su existencia física, pero no la fecha exacta de su aparición, que ha de ser en todo caso posterior al 13 de abril de 1938, en que se data el texto más tardío en él recogido, un poema de Juan Gil-Albert. Para entonces es posible que Machado ya residiera — al igual que Domenchina- en Barcelona, aunque parte de sus poemas, si no todos, fueron escritos todavía en su refugio valenciano de Rocafort «Villa Amparo», donde Domenchina lo había frecuentado el año anterior ${ }^{3}$. Del tenor de esa amistad da cuenta tanto el testimonio del propio Domenchina, poco después transportado a un exilio ultramarino en el que el recuerdo de Machado lo acompañaría de por vida, como el epistolario cruzado entre ambos durante el periodo que nos ocupa, y que tiene como asunto justamente la colaboración de Machado en el boletín.

1 A. MACHAdo, «Consejos, sentencias y donaires de Juan de Mairena y de su maestro Abel Martín», Hora de España, I (enero de 1937), p. 8.

2 Véase más abajo la cita de la nota 19. En las colecciones que conocemos del Servicio Español de Información no aparece el suplemento literario - a diferencia de lo que sucede con el suplemento gráfico «La caricatura y la guerra»-, quizá porque se tirara aparte, y luego no se encuadernó con el resto.

${ }^{3}$ La fecha del afincamiento de Antonio Machado en Barcelona no ha sido determinada con precisión por sus biógrafos, que se limitan a señalar abril del 38, basándose probablemente en el testimonio de José Machado. «A fines de la primera quincena de abril» la sitúa Bernard Sesé, con mayor concreción, aunque sin aducir pruebas (B. SESÉ, Antonio Machado (1875-1939). El hombre. El poeta. El pensador. Prólogo de Jorge Guillén. Versión Española de Soledad García Mouton. Madrid: Editorial Gredos, 1980, p. 823). La de la llegada de Domenchina a esa ciudad, por el contrario, es segura: en la noche del 16 al 17 de noviembre de 1937 él y su equipo trasladaron a Barcelona el Servicio, que no llegó a suspender su publicación un solo día (véase el editorial del n. 289 de Servicio Español de Información (Textos y Documentos), 17 de noviembre de 1937, p. 1). 
En lo que concierne a los poemas enumerados, es posible reconstruir la secuencia de los hechos: Antonio Machado hizo llegar los autógrafos a Domenchina por alguna de las vías usuales entre ellos. Este los publicó, según dijimos, en sendos suplementos del Servicio, y conservó los originales, consciente de su valor. En los meses que siguen, los sonetos vuelven a imprimirse al menos en dos ocasiones, que sepamos: en el número XVIII de Hora de España, de junio de 1938, y en una revista brasileña del mismo mes, vinculada al Servicio Español de Información, la cual reprodujo cuatro de ellos ${ }^{4}$. Entretanto, los autógrafos machadianos continúan en poder de Domenchina y, cuando el 1 de febrero de 1939 este abandona el país, figuraban entre las exiguas pertenencias que pudo llevar consigo. La noticia de la muerte del maestro el 22 de ese mes lo sorprende en Toulouse, su asentamiento provisional; escribe entonces una necrología para la prensa francesa que precisamente concluye citando los manuscritos, prueba de lo presentes que los tenía ${ }^{5}$. Y apenas unos meses más tarde, los autógrafos irán a parar, con su poseedor, al Distrito Federal de México, destino definitivo de Domenchina. Allí, en 1947, los publicó de nuevo (esta vez solo las Coplas, menos difundidas que los sonetos), en el número de homenaje que la revista Las Españas consagra a Machado ${ }^{6}$. A la muerte de Domenchina en 1959, se hizo cargo de ellos su viuda, Ernestina de Champourcin; de su mano regresaron a España a principios de los setenta. Desde 1982 paran en la Biblioteca Nacional de Madrid, donde ingresaron por compra a Durán en la subasta del 28 de mayo de ese año ${ }^{7}$.

Es, pues, improbable que las numerosas ediciones machadianas anterio-

${ }^{4}$ En cuanto a las Coplas, varios editores afirman que salieron en los números 103104 de la Revista de Las Españas en julio-agosto de ese mismo año (es de donde afirman tomarlas, por ejemplo, Julio Rodríguez Puértolas y Gerardo Pérez Herrero en fecha tardía -A. MACHADO, La guerra. Escritos: 1936-1939. Madrid: Emiliano Escolar, 1983 , p. 386-, sin indicación de página). No hemos logrado contrastar el dato: ninguna de las colecciones que conocemos de la revista llega más allá de 1936.

${ }^{5}$ «Je garde, [de] précieuses reliques, entre d'autres autographes de l'ami vénéré, les manuscrits de quatre sonnets de circonstance, écrits «Une nuit de bombardement, à Rocafort, Valencia, Mars 1938». Là, le poète[,] transpercé par la douleur de la guerre et par l'angoisse des enfants blessés, dont sa sensibilité virile écoute les plaintes, entend aussi, en dépit de sa déchéance physique qui l'incline vers la terre, le printemps déjà près d'éclore qui fait vibrer "Le son âpre de son rebec fleuri"»(J. J. DomenCHINA, «Antonio Machado (Un grand poète espagnol mort en France)», vertido al francés por E. de Champourcin. Ms. 22.263/1 BNM. Es traducción parcial — con la correspondiente puesta al día - del artículo publicado por Domenchina en La Voz el 14 de mayo de 1936 a propósito de la cuarta edición de las Poesías completas de Machado, luego recogido en las Nuevas crónicas de «Gerardo Rivera», Barcelona: Editorial Juventud, 1938, pp. 29-34).

${ }^{6}$ «Acto en recuerdo de don Antonio Machado», Las Españas, n. ${ }^{\circ} 4$ (29 de marzo de 1947), pp. 9 y 15.

${ }^{7}$ Durán, catálogo 159 , n. ${ }^{\circ} 1.164$. 
res a esta última fecha que incluyen tales poemas hayan podido tener acceso a los originales: pocos habrán sabido de su paradero, a pesar de que no era ningún secreto, si no desde su mención en la necrología de Machado - tal vez inédita, y en cualquier caso, recóndita-, al menos a partir de 1947, cuando Domenchina volvió a referirse públicamente a ellos en el susodicho número de Las Españas. Otros editores ni siquiera habrán considerado la posibilidad de que su examen revistiera interés. El hecho es que las ediciones previas a los años ochenta que hemos visto derivan, en última instancia, de las primeras versiones impresas en revistas, no del todo fieles a los manuscritos. Ni siquiera la publicada en México por José Bergamín a principios de los cuarenta se benefició de la cercanía material de los autógrafos, seguramente más por inadvertencia que por voluntad de aquel, para esas fechas ya enemistado con Juan José Domenchina. La única edición que presumiblemente hubiera reimpreso la versiones autógrafas - la antología de Antonio Machado que por entonces proyectaba el propio Domenchina para la editorial Centauro- no llegó a ver la luz ${ }^{8}$.

Así pues, las versiones del Servicio Español de Información constituyen la princeps de estos poemas. En lo que de él conocemos - los ocho sonetos-, el boletín proporciona un texto razonablemente limpio y escrupuloso con el original. Ignoramos si Machado llegaría a corregir pruebas o si por el contrario confió esa tarea a Domenchina. La escasa entidad de las discrepancias entre los manuscritos y el impreso más bien parecen apuntar a esto último, como también el alejamiento físico entre autor y editor cuando Machado escribe todos o parte de los poemas ${ }^{9}$. Dejando a un lado las variantes de orden tipográfico (supresión de las mayúsculas a comienzo de verso en el Servicio en los cuatro sonetos de la primera serie, que sí las tienen en el manuscrito; minúscula en los nombres de los meses, frente a la oscilación de los autógrafos), alguna otra puede haber sido iniciativa de Domenchina, o de los cajistas, como la posposición del paréntesis en el título «Amanecer en Valencia (Desde una torre)», conforme a lo que parece dictar el buen sentido, y en contra del original ${ }^{10}$. En el primer verso de

${ }^{8}$ No recoge sin embargo Domenchina ninguno de los poemas en su selección machadiana para la Antología de la poesía española contemporánea (1900-1936) (México: Editorial Atlante, 1941), indicio de que el lugar que ocupaban en su estimativa en esos años iniciales del exilio no era en todo caso de primer orden.

9 A diferencia de otras cartas donde Machado solicita galeradas a Domenchina, en las tres que creemos vinculadas a estos poemas no lo hace (en una, expresamente, delega ese cometido: cf. infra, nota 50).

${ }^{10}$ El cambio se ha consolidado en la tradición de ese soneto. Del examen del autógrafo puede conjeturarse que el título primitivo fuera «Desde una torre. Amanecer en Valencia», y que el paréntesis sea un añadido posterior del poeta — «(Desde una torre). Amanecer en Valencia»-, lo que ocasionó la anomalía. Sin embargo, la anteposición del paréntesis no solo responde a la voluntad del autor, sino que facilita la correcta interpretación del poema, como veremos. 
ese mismo soneto se justifica igualmente que el Servicio Español de Información haya suprimido la coma tras «desvanes» antes de un inciso:

Estas rachas de Marzo, en los desvanes,

-Hacia la mar- del tiempo; la paloma...,

es la transcripción paleográfica del manuscrito. Ese empleo de coma ante raya o paréntesis, bastante extendido en la época, lo hallamos en varios más de los textos que aquí nos ocupan, y también en otros lugares de la poesía machadiana, propensa a la reflexión parentética. Resulta en cambio infundada la omisión por el Servicio de la coma tras un complemento de lugar en el v. 5 de «El poeta recuerda las tierras de Soria»:

\section{$5 \quad$...En la memoria mía,}

tu recuerdo a traición ha florecido...

Despiste del boletín habrá de ser la ausencia del signo de admiración ante «Oh» en «La muerte del niño herido», v. 6; posible interpretación errónea, la minúscula al comienzo del siguiente verso (es uno de los poemas que en el autógrafo ponen mayúscula en todas las iniciales de verso):

$\ldots-i$ Oh, flor de fuego!

¿Quién ha de helarte, flor de sangre, dime?

La minúscula «quién» se defendería mejor si hubiera una coma tras la invocación anterior, que convirtiera a la primera frase propiamente en un vocativo; pero tal coma no existe en el original. La presencia de dos vocativos en una misma oración («...—iOh, flor de fuego![,] / ¿quién ha de helarte, flor de sangre, dime?) parece además poco económica. Supeditación excesiva del Servicio al manuscrito es, por su parte, haber mantenido sin tilde tanto el «Tú» pronominal en «De mar a mar entre los dos la guerra» (v. 4) como el «ítalo» de «Otra vez el ayer. Tras la persiana» (v. 11), conforme al autógrafo, nada riguroso con la acentuación. E hipercorrecciones, la acentuación exclamativa en «cuánto» (vv. 10, 11 y 13 de «Trazó una odiosa mano, España mía») y la sustitución del número «II» por un «IV» ante «Mas tú, varona fuerte, madre santa», último, en efecto, de los cuatro sonetos de su serie, pero segunda parte del que le precede; la primera rectificación constituye un disparate palmario que obra en contra de la hipótesis de que Machado haya podido supervisar la impresión de los textos, y la segunda, un precedente con larga y equívoca descendencia. Esa es, pues, sin considerar las Coplas, la lista completa de lugares discutibles, entre alteraciones deliberadas e indeliberadas y adhesiones indebidas, de los cuales dos - la coma omitida en «El poeta recuerda las tierras de Soria» y la numeración de «Mas tú, varona fuerte, madre santa»— son errores que no podían ser advertidos por el discreto lector. 
La fidelidad del Servicio Español de Información alcanza a la distribución de los poemas, que constituyen dos series bien diferenciadas, publicadas incluso en páginas distintas ${ }^{11}$. Es dato relevante, sobre el que habremos de volver. Solamente la continuidad entre «Trazó una odiosa mano, España mía» y «Mas tú, varona fuerte, madre santa», a la que acabamos de referirnos, se rompe por aparecer los cuatro sonetos del ciclo La guerra numerados correlativamente en romanos, del I al IV.

Es el Servicio Español de Información, sin lugar a dudas, fuente del semanario brasileño Gaceta Hispana, que en junio de 1938 reproduce el ciclo de sonetos «escritos una noche de bombardeo, etc.» ${ }^{12}$. La publicación, abiertamente afecta a la República española, se venía editando en São Paulo desde abril de 1936 por Argemiro C. Monteiro y L. Vidal Reis. Del suplemento correspondiente de Servicio Español de Información son calco incluso alguna peculiaridad tipográfica y el epígrafe global de la sección («Poesía Española. Suplemento Literario de Gaceta Hispana»). Se trata de un extracto de la antología poética reunida en el boletín español, donde tienen cabida asimismo obras de Unamuno, Serrano Plaja, Garfias, Altolaguirre y Domenchina. Los sonetos machadianos se disponen en dos columnas de dos; la ausencia de numeración diluye un tanto su orden, que no ha sido alterado con voluntad expresa.

Probablemente también el Servicio habrá sido el dechado de una publicación con mayor trascendencia: el n. ${ }^{\circ}$ XVIII de Hora de España, del mismo junio de 1938, donde figuran los ocho sonetos ${ }^{13}$. La filiación puede

${ }^{11}$ El ejemplar consta de cuatro páginas, de tamaño DIN-A 3. Una advertencia en página 2 indica que todos los poemas son inéditos. En p. 1, una columna encabezada por el epígrafe «La Guerra» recoge cuatro sonetos de A. Machado sin fechar, numerados del I al IV: «De mar a mar entre los dos la guerra», «Otra vez el ayer. Tras la persiana», «Trazó una odiosa mano, España mía», «Mas tú, varona fuerte, madre santa». Ninguno de los cuatro presenta lema o título. En otra columna, esta vez de la p. 3, aparecen los sonetos restantes, bajo el marbete de «Cuatro sonetos», y la precisión «(Escritos una noche de bombardeo en Rocafort (Valencia), Marzo de 1938)». Van numerados en romanos, del I al IV, cada uno con un rótulo: «La primavera», «El poeta recuerda las tierras de Soria», «Amanecer en Valencia (Desde una torre)», «La muerte del niño herido». Así pues, la fecha de marzo de 1938, en rigor, solo corresponde a estos cuatro últimos.

${ }^{12}$ A. Machado, «Cuatro sonetos», Gaceta Hispana, n. ${ }^{\circ} 100$ (4 de junio de 1938), p. 3.

13 A. Machado, «Verso», Hora de España, XVIII (junio de 1938), pp. 5-11. Además de los sonetos aquí comentados, incluye el dedicado a Líster («Tu carta —oh noble corazón en vela») y la cuarteta a Federico de Onís («Para ti la roja flor»). El orden es: I) «Más fuerte que la guerra —espanto y grima—»; II) «iYa su perfil zancudo en el regato...!»; III) «Estas rachas de marzo, en los desvanes»; IV) «Otra vez en la noche... Es el martillo»; V) «De mar a mar entre los dos la guerra»; VI) «Otra vez el ayer. Tras la persiana»; VII) «Trazó una odiosa mano, España mía»; VIII) «Mas tú, varona fuerte, madre santa». Según Antonio Sánchez Barbudo, secretario de la revista en una etapa, aunque el número lleva fecha de junio, en realidad salió meses más tarde (A. SÁnCHEZ BARBUDO, Ensayos y recuerdos. Barcelona: Editorial Laia, 1980, p. 17). 
establecerse por algún error común, como se comprobará en los aparatos críticos que damos más adelante. Ese argumento interno está respaldado por la ausencia de pruebas externas que refuten nuestra hipótesis: no existe constancia de que Domenchina haya cedido los manuscritos a la redacción de esa revista, ni tampoco parece haberla de que Machado directamente proporcionara un apógrafo. Ambas posibilidades, aunque verosímiles, son a nuestro juicio más improbables que la que aquí sostenemos, por más que la relativa vecindad de todos los implicados mueva acaso a pensar lo contrario: ni las relaciones de Domenchina con el equipo redactor de Hora de España eran precisamente cordiales, a pesar de que colaborara un par de veces en la revista, ni tiene mucho sentido que Antonio Machado entregase a una publicación editada en Barcelona un duplicado autógrafo (y alterado) de unos textos recién impresos en la misma ciudad. Más bien los responsables de la revista los tomarían, por su cuenta, del periódico que tenían a mano distribuido gratuitamente, y que en cada número invitaba a la difusión de su contenido con llamadas expresas. Tampoco parece probable que, de haber supervisado el autor personalmente la composición de los textos, pasara por alto algunos de los errores e imprecisiones que se han deslizado. Una vez más, es el cotejo de los poemas el que nos lleva a suponer que el control directo de Machado sobre la fase de impresión hubo de ser escaso o nulo, y que las variantes originadas no se deberán a rectificaciones del autor en pruebas, sino a la intervención premeditada o involuntaria de los editores. La cuestión de la autoridad de ese número XVIII de Hora de España es en todo caso capital, pues él, mucho más conocido que el suplemento literario del Servicio Español de Información, es la base probable del grueso de ediciones posteriores.

Fundamentalmente, se le deben tres malhadadas aportaciones, que han hecho fortuna en la tradición ecdótica de estos poemas. Dos de ellas se explican sin dificultad, en el proceso de composición de los textos: una es el cambio del género del determinante indefinido en el verso quinto del célebre «De mar a mar entre los dos la guerra»:

Tú asomada, Guiomar, a un finisterre,

5 miras hacia otra mar, la mar de España que Camoens cantara, tenebrosa.

«Otra mar» es lo que se lee claramente en el autógrafo, pero tanto Hora de España como los sucesivos editores, salvo excepción, imprimen un masculino «otro mar», que choca con las tres apariciones de la palabra «mar» en femenino a lo largo de los cuartetos; el contraste es especialmente violento en ese verso 5 por la aposición en femenino.

La segunda novedad es la asignación de la fecha de marzo de 1938, propia de los cuatro primeros sonetos («Más fuerte que la guerra - espanto y grima—», «iYa su perfil zancudo en el regato...!», «Estas rachas de 
marzo, en los desvanes» y «Otra vez en la noche... Es el martillo»), al conjunto de los ocho, publicados en Hora de España como una única sucesión con numeración seguida, y así considerados a partir de ese momento. La indicación de tal fecha y el lugar de composición (Rocafort) aparece tras el último soneto, «Mas tú, varona fuerte, madre santa», por lo que también puede interpretarse como exclusiva de este (que es lo que hacen casi todas las ediciones derivadas de Hora de España). Se pierde además la referencia del epígrafe primitivo a la noche de bombardeo en que fueron escritos los cuatro primeros poemas.

Queda por el contrario sin aclarar el origen de otra de las discrepancias más notorias entre el texto proporcionado por autógrafos y Servicio Español de Información, y el de Hora de España: el rótulo «(A otro conde D. Julián)» que en esta última encabeza el soneto «Mas tú, varona fuerte, madre santa» y que, de no haber participado el autor en la impresión, habrá que atribuir a algún espontáneo. En ello insistiremos luego.

La primera inclusión de los poemas en volumen se produce tempranamente, en 1940, y lejos de España: las Obras de Antonio Machado publicadas por la editorial Séneca de México bajo la dirección de José Bergamín y al cuidado tipográfico de Emilio Prados, recogen los ocho sonetos, con numeración corrida, y en el orden habitual ${ }^{14}$. El examen muestra que el modelo es Hora de España, a cuyo consejo de colaboración había pertenecido Bergamín ${ }^{15}$. Como primicia, introducen en el v. 6 de «Estas rachas de marzo, en los desvanes» la lectio facilior «levantina», sentando un precedente que llegará hasta el cuerpo principal de una edición crítica medio siglo después ${ }^{16}$ :

...y el sol que asoma,

5 bola de fuego entre morada bruma,

a iluminar la tierra valentina...,

14 A. Machado, Obras. México: Editorial Séneca (Col. «Laberinto»), 1940, pp. 851856. No contienen en cambio los poemas de guerra las Poesías completas de Antonio Machado publicadas en Buenos Aires-México por Espasa Calpe Argentina apenas un mes después, en noviembre de 1940.

${ }^{15}$ El texto presenta no obstante un error privativo común con el Servicio Español de Información, que puede ser coincidencia: la hipercorrección "cuánto" en los vv. 10, 11 y 13 de «Trazó una odiosa mano, España mía».

${ }_{16}$ No es poca repercusión para tratarse de un trabajo sin «pretensiones definitivas», según palabras de Bergamín en el prólogo: «No apuramos con ello enteramente la obra del poeta. Algo pudiera todavía habérsenos escapado de inédito. No es esta que hacemos ahora una edición con pretenciones [sic] definitivas» (J. Bergamín, ap. A. MACHADO, Obras, ed. cit., p. 19). Parece inferirse que el editor sí cree haber apurado la obra édita; pero desconoce, como se ve, la publicación de al menos «Papagayo verde»y «Sobre la maleza». 
es la lectura correcta. Constituyen también estas Obras el testimonio más antiguo en que la conjunción adversativa que inicia el soneto «Mas tú, varona fuerte, madre santa» aparece convertida en adverbio de cantidad, prueba no ya solo del escaso oído de ciertos editores, sino también de que la solución de continuidad con el soneto anterior está consumada.

La Editorial Losada de Buenos Aires, en su proyecto de reunir las obras completas de Antonio Machado, publica en 1943 un volumen con sus Poesías, sin indicación de responsable ni prólogo ${ }^{17}$. Es la primera que reúne las diez composiciones, hecho meritorio, como asimismo lo es que se aparte de la corriente del uso previa y venidera en leer bien el sintagma «otra mar» del soneto a Valderrama (v. 5). En contrapartida, estraga lamentablemente otro soneto, «iYa su perfil zancudo en el regato...!», por omisión de un verso entero; también el primer terceto de «Trazó una odiosa mano, España mía» resulta dañado por la conversión del «cuanto» de la anáfora en un «cuando» (v. 10). La obra ha tenido varias reediciones, con tiradas abundantes, sin que tales averías, y otras menos visibles, se hayan subsanado.

Un año después, en agosto de 1944, concluye la impresión en la misma Buenos Aires de una nueva edición de la poesía de Antonio Machado, la de Pleamar. Recoge igualmente los diez poemas, con un texto posiblemente tomado de Hora de España para los sonetos ${ }^{18}$. El hito siguiente se produce en marzo de 1947 en México, cuando Juan José Domenchina menciona en Las Españas los autógrafos y reproduce las Coplas, creyéndolas no reimpresas desde su salida en el Servicio Español de Información ${ }^{19}$. Salvo fallo de memoria, la inexactitud indica que no fue él el promotor de la inclusión de los poemas en la Revista de las Españas en 1938, si es que esta se produjo, y que en ese caso tampoco cedería los originales.

En octubre de 1959, coincidiendo por casualidad con la muerte de Domenchina en México, sale en Italia la edición machadiana más ambiciosa hasta esas fechas: las Poesie di Antonio Machado, por Oreste Macrí,

17 A. Machado, Poesías. Buenos Aires: Editorial Losada, 1943. Los textos se incluyen en una sección de «Poesías de la guerra» que se abre con las Coplas (pp. 251252); los sonetos están en las pp. 256-260, en el orden consabido, numerados del I al VIII, y con la fecha de «Rocafort, marzo 1938» cerrando el último.

18 A. Machado, Obra poética. Epílogo de Rafael Alberti. Buenos Aires: Editorial Pleamar, 1944. Las coplas aparecen en pp. 332-333, y los ocho sonetos en pp. 337-342, con la disposición y numeración habituales.

19 «Luego de subrayar, en esta recordación promovida por Las Españas, el carácter indeleble de la poesía de Antonio Machado, yo, con el propósito de coadyuvar de alguna manera a la eficacia del homenaje que se le tributa, me reduzco a transcribir algunas canciones suyas, poco menos que inéditas, ya que, aunque publicadas durante la guerra civil, en el primer suplemento literario del "Servicio Español de Información", todavía no se han recogido en volumen, cuyo autógrafo conservo como preciosa reliquia» (J. J. Domenchina, «Acto en recuerdo de don Antonio Machado», Las Españas, n. o 4, 29 de marzo de 1947, p. 15). El acto se celebró en la Editorial Séneca el 19 de febrero, con motivo del octavo aniversario de la muerte de Machado. 
edición pretendidamente crítica, pero en rigor solo comentada, y bilingüe, con una meritísima traducción italiana en verso y extensa bibliografía ${ }^{20}$. Ninguno de los poemas que nos ocupan figura en ella. Sí se recogen todos, en cambio, sin novedades textuales ni de ordenación, en la segunda edición de la obra, dos años después ${ }^{21}$. Del cotejo se infiere que el editor no ha tenido a la vista las versiones del Servicio Español y Hora de Espa$\tilde{n} a$ que menciona como fuentes, sino las Poesías de guerra de Antonio Machado reunidas por Aurora de Albornoz en Puerto Rico el mismo año de $1961^{22}$. De ahí acaso que «la tierra valentina» («Estas rachas de marzo, en los desvanes», v. 6) de autógrafo, Servicio Español de Información y Hora de España se simplifique una vez más en «levantina», como ya sucediera en la edición de José Bergamín, posible modelo de Albornoz para los sonetos («la terra levantina a illuminare», en la versión toscana de Macrí) ${ }^{23}$.

El libro de Aurora de Albornoz no es solo una edición de la poesía machadiana de guerra, sino también su estudio. Lo específico del contenido induce a pensar que se habrá extremado el prurito filológico; nada más lejos de la realidad: la autora desconoce los autógrafos, y tampoco se atiene, como vemos, a las versiones de las primeras revistas, de modo que se limita a repetir e incrementar los errores heredados de los editores previos. Tres años después, la propia Albornoz, junto con Guillermo de Torre, dio a las prensas una nueva entrega machadiana, «la primera edición de sus obras que puede considerarse completa», en palabras de este último ${ }^{24}$. Su

${ }^{20}$ Poesie di Antonio Machado. Studi introduttivi, testo criticamente riveduto, traduzione, note al testo, commento, bibliografia, a cura di Oreste Macrí. Milano: Lerici editori, 1959, $700 \mathrm{pp}$.

${ }_{21}$ Poesie di Antonio Machado. Studi introduttivi, testo criticamente riveduto, traduzione, note al testo, commento, bibliografia, a cura di Oreste Macrí. Milano: Lerici editori, 1961 (II edizione completa), $1.392 \mathrm{pp}$. Los ocho sonetos se encuentran en las pp. 1.080-1.089, seguidos del soneto a Líster y la cuarteta a Onís, bajo el epígrafe «Verso (9 sonetos y una cuarteta)», lo que desvirtúa aún más las para entonces ya del todo olvidadas relaciones internas entre los poemas. En pp. 1.098-1.103 aparecen las Coplas. Las páginas pares contienen el texto español y las impares la correspondiente traducción al italiano. Una tercera edición salió en 1969.

22 A. DE Albornoz, Poesías de guerra de Antonio Machado. San Juan de Puerto Rico: Ediciones Asomante, 1961. Impresas en Gráfica Panamericana de México, D. F., con una tirada de mil ejemplares. Los sonetos aparecen en las pp. 77-84, numerados del I al VIII, sin distinción de series; en pp. 93-97, se localizan las Coplas. Publicado en agosto de ese año, es seguro que Macrí llegó a conocerlo, pues figura en su bibliografía.

23 «Queste raffiche a marzo, sui ripiani», v. 6, Poesie di A. M., 2a ed. cit., p. 1.083.

24 A. Machado, Obras. Poesía y prosa. Edición reunida por Aurora de Albornoz y Guillermo de Torre. Ensayo preliminar por Guillermo de Torre. Buenos Aires: Editorial Losada, 1964, p. 7. La afirmación, como se ve, pasa por alto la monumental edición ampliada de Macrí, acaso como tácita respuesta al uso que este había hecho de la anterior edición de Albornoz. Los sonetos se recogen en pp. 648-652, numerados del I al VIII, y en el orden sabido; las coplas figuran en pp. 656-657. 
base son las Poesías de guerra de 1961, con alguna variante de puntuación, acaso por influencia de Pleamar. En 1997 la obra iba por su cuarta edición.

La primera edición de Albornoz-Torre se acabó de imprimir en Buenos Aires en agosto de 1964. Pocos meses atrás, en febrero, el Consejo Nacional de Cultura de La Habana había impreso con una tirada de cuatro mil ejemplares otras Poesías completas de Antonio Machado que contienen los diez poemas ${ }^{25}$. La edición concluye con una «Imagen sucesiva de Antonio Machado» a cargo de Rafael Alberti (pp. 377-390), epiloguista, como vimos, también de la publicada veinte años atrás por la bonaerense Pleamar, sin duda antígrafo de esta.

Llegamos así a la que es la edición machadiana por antonomasia, y la más conocida en España: la de las «Selecciones Austral» de Espasa Calpe. La vinculación de Antonio Machado a ese sello editorial se remonta, como es sabido, nada menos que a 1919, cuando la vieja casa Calpe publicó la segunda edición de Soledades, galerías y otros poemas. Posteriormente, ya constituida como tal, Espasa Calpe ha venido publicando las Poesías completas de Antonio Machado desde su segunda edición en 1928 a nuestros días; hasta la cuarta edición (1936), con el beneplácito del poeta. Hubo que esperar, sin embargo, al 24 de noviembre de 1975 para ver en la calle la primera que incluye algunos de los poemas que nos ocupan ${ }^{26}$. Por fin la poesía machadiana de guerra tenía cabida en unas poesías completas editadas en España, tras la proverbial apropiación política de los hermanos Machado por facciones opuestas durante el franquismo ${ }^{27}$. Hasta enero de 1988 , en que fue modificada, la obra se reeditó en doce ocasiones ${ }^{28}$. Las

${ }^{25}$ A. Machado, Poesías completas. La Habana: Consejo Nacional de Cultura, 1964. Se inscriben en la sección «Poesías de la guerra». Las coplas «Papagayo verde» y «Sobre la maleza» ocupan las pp. 365-367; los ocho sonetos aparecen, con numeración correlativa, en las pp. 371-376.

${ }^{26}$ A. Machado, Poesías completas. Prólogo de Manuel Alvar. Madrid: Espasa Calpe («Selecciones Austral»), 1975, 424 pp.

${ }^{27}$ Los poemas de guerra de Antonio Machado no figuran en ninguna de las ediciones de sus poesías completas publicadas por Espasa Calpe durante el franquismo. Tampoco se recogieron en otra importante edición española, las Obras completas de Manuel y Antonio Machado publicadas en Madrid por Plenitud en 1947, y reimpresas en seis ocasiones hasta 1973, con texto al cuidado de Heliodoro Carpintero. Excepcionalmente, uno de los poemas que estudiamos, el soneto «Estas rachas de marzo, en los desvanes», se había reproducido en el Almanaque. Destino. 1944 (Barcelona: Destino, 1943), p. 34, con el título «Marzo».

${ }^{28}$ Para medir su repercusión, a esas cifras habría que sumar las ediciones que derivan de ella, como la Poesía de Antonio Machado publicada en Estella por Ediciones Orbis en 1988. Se trata de una edición especial para la Caja de Ahorros y Monte de Piedad de Castellón, sin prólogo, supuestamente de la obra completa, según el ISBN. Recoge los sonetos «La primavera», «El poeta recuerda las tierras de Soria», «Amanecer en Valencia...» y «La muerte del niño herido» (pp. 347-349) y las dos Coplas (pp. 351-352). 
arbitrariedades y errores en que incurre nos obligan a detenernos en ella, dados la difusión y el predicamento de que goza. Para empezar, tres de los sonetos que estudiamos - los tres últimos del ciclo La guerra- faltan en tales Poesías completas, menos completas, por tanto, de lo que su título indica ${ }^{29}$. El primero de esa serie, «De mar a mar entre los dos la guerra», se ha colado entre unos inexistentes como tales «Dos sonetos a Guiomar», formando parte del «Cancionero apócrifo», triquiñuela acaso para burlar la censura $^{30}$. La edición no señala la procedencia de los textos; tampoco se indican los criterios editoriales. Varias de sus adiáforas más notables parecen enmiendas ope ingenii; resta saber a quién haya que achacarlas, puesto que Manuel Alvar, como acabamos de ver, no responde del texto publicado desde 1975 a 1987: así, por ejemplo, el sorprendente «cielo de ballesta» (por «vuelo de ballesta») en el segundo verso de «iYa su perfil zancudo en el regato...!»; la «dorada bruma» —en vez de «morada bruma»— de «Estas rachas de marzo, en los desvanes» (v. 5); el comienzo «Otra vez es la noche...» (por «Otra vez en la noche...») en La muerte del niño herido; «tu llama» por «la llama» en «De mar a mar entre los dos la guerra» (v. 11); para no entrar en las numerosas variaciones de puntuación (sirva como ejemplo el punto tras «fría» en el primero de los sonetos citados, v. 8, que transforma el vocativo «Soria pura, entre montes de violeta» del verso siguiente en una oración nominal).

A partir de su décimotercera entrega, de 1988, se trata de una edición aumentada y corregida, que sí contiene ya los diez poemas que nos interesan, presuntamente revisados por Manuel Alvar, que esta vez sí se adjudica la responsabilidad ${ }^{31}$. Pero el texto es prácticamente idéntico al de 1975

${ }^{29}$ En su edición de 1988 Alvar no se hacía responsable del texto de 1975, reimpreso, como decimos, sin cambios hasta entonces: «La edición que hoy ofrecemos quiere ser de las Poesías completas de Antonio Machado, cosa que no eran las que se amparaban bajo tal rúbrica. Resulta sorprendente que hayan hecho falta en España tantos años para que se incluyeran en el conjunto los poemas de la guerra civil. Tanto más extraño por cuanto las dificultades parecían no existir. Al poner el prólogo a la edición de "Selecciones Austral" se me pidió revisar los textos; mis condiciones eran muy sencillas: debían ser las Poesías completas, según rezaba el título. Al parecer, y así se me dijo, la censura dejaba publicar todo, menos la cabecera A otro conde D. Julián (todo incluía también el texto "Más que [sic] tú, varona fuerte, madre santa"). Hubo escrúpulos que no casaban con mi visión de las cosas y rogué que constara con toda claridad que yo sólo respondía del prólogo. Y así se hizo. Era el mes de noviembre de 1975» (A. MACHAdo, Poesías completas. Edición de M. Alvar. Madrid: Espasa Calpe («Colección Austral»), 1988, p. 85).

30 A. Machado, Poesías completas, ed. de 1975 cit., p. 360. El otro soneto es «Perdón, Madonna del Pilar, si llego». Este vuelve a reproducirse en la p. 412, en la sección «De Mairena póstumo», reiteración que, de ser deliberada y no mero despiste, resulta ociosa. El resto de los poemas se agrupan bajo el epígrafe «Poesías de guerra (1936-1939)», pp. 413-417.

31 «Presento, pues, toda la poesía de Antonio Machado. Los textos publicados por él en las Poesías completas no ofrecen muchas dificultades en una presentación como esta, 
(incluidos los cinco errores de lectura que acabamos de ver). Desde su vigésimosexta edición, de septiembre de 1997, el libro se viene imprimiendo con un apéndice didáctico ${ }^{32}$.

Entretanto, Julio Rodríguez Puértolas y Gerardo Pérez Herrero han publicado en 1983 la citada colección de escritos machadianos de guerra, que incluye los poemas ${ }^{33}$. A cuarenta y cinco años de su redacción, el proceso de deformación de los textos prosigue inexorable su curso:

\section{...-Madrid, ¡el pájaro amarillo!,}

es el estupefaciente destino del vocativo «Madre, ¡el pájaro amarillo!» en La muerte del niño herido (v. 3); en unas plurales «hojas de nopal» se ha convertido a su vez la «hoja de nopal» con la que se identifica al olvido en «Papagayo verde» (v. 7). Al año siguiente, el gobierno de Valencia edita un lujoso volumen en homenaje al autor donde también aparecen los poemas, seguramente tomados del propio libro de Rodríguez Puértolas y Pérez Herrero, con el que coincide en lecturas privativas como las mencionadas - la primera haría las delicias de una publicación con sesgo político como la valenciana-, y a las que añade alguna más, entre otras licencias ${ }^{34}$.

Llamada a reparar este estado de cosas estaba la edición en más de dos mil quinientas páginas de la obra completa de Antonio Machado a cargo de Oreste Macrí, aparecida en 1988, cuando los autógrafos que estudiamos eran ya de dominio público ${ }^{35}$. Y, en efecto, a diferencia de sus antecesores —y de lo que él mismo hiciera en 1961 - el profesor Macrí esta vez sí colacionó los manuscritos: tarea ciertamente inexcusable, tratándose de una edición crítica, y concienzuda. Sin embargo, por alguna razón no explica-

e incluso fueron bien publicados en ediciones de carácter popular. No puedo decir lo mismo de los que no se recogieron por el autor y que, tantas veces, se han impreso con muchos errores. Como principio he querido dar unos textos tan limpios como los de la primera parte. He revisado la totalidad de la obra» (Manuel Alvar: «La presente edición», ap. A. MACHADO, Poesías completas. Edición de 1988 cit., p. 85).

32 A. Machado, Poesías completas. Soledades / Galerías / Campos de Castilla... Edición de Manuel Alvar con un apéndice de $\mathrm{M}^{\mathrm{a}}$ Pilar Celma. Madrid: Espasa Calpe, 1997, 529 pp.

33 A. MAChado, La guerra. Escritos: 1936-1939. Colección, introducción y notas de Julio Rodríguez Puértolas y Gerardo Pérez Herrero. Madrid: Emiliano Escolar, 1983, 488 pp.

34 Valencia a Machado. Valencia: Generalitat Valenciana, 1984, pp. 47-61 y 65-67. Por ejemplo, los «manes del odio y de la cobardía» del penúltimo soneto (v. 5) se han transformado en «manos»; la copla «Sobre la maleza» presenta un colofón de cuatro versos.

35 Se trata de una edición de dos tomos en papel biblia con un total de $2.545 \mathrm{pp}$., el primero dedicado a las Poesías completas. Edición crítica de Oreste Macrí con la colaboración de Gaetano Chiappini. Madrid: Espasa-Calpe / Fundación Antonio Machado, 1988, 1.032 pp. La contribución de Chiappini se limita a tareas ancilares reseñadas en p. 4, ninguna de las cuales parece afectar a nuestros poemas. 
da, se atuvo en el cuerpo principal de los poemas referidos a su versión impresa, y arrinconó las variantes de los autógrafos en las notas ${ }^{36}$. Eso sin contar algún cambio menor que introduce de su propia cosecha, sin el respaldo de ninguna fuente y sin advertirlo. Tal criterio de dar preeminencia al impreso sobre el manuscrito, válido seguramente para los textos reunidos en volumen por el propio Machado, resulta a nuestro juicio discutible en el caso de unos poemas exclusivamente aparecidos en revistas en vida del poeta, y en el fragor de una guerra. Como hemos dicho, nada hace pensar que las diferencias existentes entre los originales y esas primeras ediciones se deban a rectificaciones del autor en pruebas, y no a descuido o inspiración de los impresores. No hay que olvidar que los textos salieron por vez primera en una publicación cuya prioridad era la propaganda política, no la pureza filológica, a despecho del cuidado que Domenchina siempre puso en todo lo que hacía. Y que ni siquiera ella, rigurosa pero poco accesible, ha sido la base de los siguientes editores tanto como Hora de España, más alejada del designio primitivo del autor. Ninguna de las dos cuenta con su visto bueno, mientras no se demuestre lo contrario. Pero Macrí no parece considerar excepcional el caso de los poemas sueltos, ni argumenta, por lo demás, sus criterios editoriales. Todo ello tiene, naturalmente, mayores repercusiones en una edición crítica que en una edición común. La consecuencia es que se acaba dando carácter canónico equiparable al de las Poesías completas autorizadas por Machado en 1936, a textos, cuando menos, dudosos.

No mayor certidumbre proporciona su edición en lo que concierne a otra labor controvertida: la puntuación de los textos. Echamos en falta en el minucioso estudio preliminar una reflexión al respecto. El editor no advierte si reproduce o enmienda la puntuación del poeta; se entendería pues, por omisión, que hace lo primero, si no fuera porque la experiencia demuestra la facilidad con que los editores acostumbran a intervenir en ese punto sin mención expresa, como en efecto ha sucedido en esta ocasión. Prueba de la escasa importancia que Macrí concede a ese aspecto es que no registra las variantes de puntuación de los autógrafos. Bien es verdad que en ello no difiere del común de los editores de poesía, sorprendentemente despreocupados ante un rasgo a nuestro juicio fundamental en el

${ }^{36}$ Se diría que su propia edición de 1961 - si no su avanzada edad- ha pesado demasiado en el criterio del editor, contrario a alterarla en lo esencial treinta años después incorporando las novedades. Así, se ha limitado a consignar en letra pequeña las discrepancias de los autógrafos, sin prestarles apenas atención, como mera coletilla al texto definitivamente constituido en 1961. Para colmo de males, la nota de los sonetos aparece por error en el lugar correspondiente a las Coplas y viceversa, con lo que las lecturas del autógrafo pasarán inadvertidas a la mayoría de los lectores, pues la errata no es fácil de detectar. Existen asimismo varios errores en las entradas de la bibliografía correspondientes a estos textos (t. I, p. 265, núms. 73 y 77). 
idiolecto de un escritor contemporáneo. Así que el lector no sabe a qué atenerse.

Discutible es, asimismo, la disposición de los poemas. La falta de fechas precisas (por su desatención también en eso a los autógrafos) mueve a Macrí a agruparlos en bloque, mezclándolos con otros de la misma época, y rompiendo la unidad existente entre varios de ellos. Ahí, una vez más, se deja llevar por la inercia en lugar de ponerle freno.

La obra se reeditó en cuatro volúmenes en febrero de 1989, y tuvo pronto dos reimpresiones, en marzo y mayo de ese año ${ }^{37}$. Recientemente se ha reproducido a plana y renglón y a precio módico, bajo el logotipo conjunto de RBA y el Instituto Cervantes, en una colección de «Grandes Autores de la Lengua Española» que hoy se encuentra en los quioscos españoles $^{38}$. Se populariza así, con sus méritos y sus fallas, un trabajo de hace más de quince años (en rigor, de hace más de cuarenta, pues su texto, como decimos, es básicamente el de 1961), sin enmienda, y como si nada hubiera pasado desde entonces en los estudios machadianos. No parece que sea el mejor tributo a la memoria del profesor Macrí, ni lo que cabría esperar de tan docta institución. Los numerosos autógrafos salidos a la luz en los últimos años (Cuadernos de Burgos y Sevilla) reclaman por el contrario - y hacen posible - una revisión exhaustiva no ya solo de la obra dispersa, sino del conjunto de la poesía machadiana, que complete la enorme labor llevada a cabo por Oreste Macrí ${ }^{39}$.

En resumen: donde unos aciertan otros yerran, y no hay un solo testimonio que proporcione textos inmaculados. De tales ediciones globales se nutre directa o indirectamente el resto: antologías individuales y colectivas, selecciones escolares, traducciones, citas y extractos, ya sea impresos o en soporte informático. Huelga comentar la presencia de los poemas en ese tipo de publicaciones de segundo o tercer grado, imposible de controlar, por lo demás, en un autor de tamaña magnitud: todas las que hemos consultado - no pocas excelentes - acusan en alguna medida las secuelas de su origen. Su reseña minuciosa nada aportaría a lo ya sabido: el error es fecundo por naturaleza.

$$
* \quad * \quad *
$$

37 A. Machado, Poesías completas, t. II de Poesía y prosa (Edición crítica de Oreste Macrí con la colaboración de Gaetano Chiappini. Madrid: Espasa-Calpe / Fundación Antonio Machado, 1989, 2.545 pp. en 4 tomos).

38 Antonio MACHADO, Obras completas. Edición crítica de Oreste Macrí con la colaboración de Gaetano Chiappini. Barcelona: RBA, 2005. En la fecha en que escribimos esto acaba de salir el tomo I, correspondiente a la poesía.

39 Del fondo de Burgos aún tuvo ocasión de servirse Macrí en su Opera poetica. «Poesías completas»e «Sueltas» de A. Machado, «nuova edizione» reunida en 1994 (Florencia: Le Lettere). Pero la obra no contiene novedad en lo que respecta a nuestros poemas, fieles a la versión de Lerici. 
Transcribimos a continuación el texto que de los diez poemas proporcionan los autógrafos. Se respeta la unidad interna de las series (cada una de ellas lleva en la última página del manuscrito firma del autor, como completa). Se mantiene igualmente la puntuación de los originales, incluso cuando nos parece mejorable. Solo hemos intervenido - siempre con advertencia previa- para restaurar algún signo de admiración y en aquellos lugares donde Machado transgrede la norma actual que impide poner coma ante raya o paréntesis. Del mismo modo, se corrige la ortografía de los manuscritos (ausencia de algunas tildes, incorrecciones en palabras extranjeras, regularización de minúsculas en los nombres de los meses). No es una edición paleográfica (Machado pone en mayúsculas todas las iniciales de verso en la primera serie de sonetos, como se dijo).

Aunque aventuramos algunas observaciones acerca del contenido, no es nuestra intención hacer un análisis pormenorizado de los textos ni su valoración estética. Lo que no significa que compartamos la escasa estima en que los tienen no pocos estudiosos. Nos parece, por el contrario, merecida la reivindicación que de los sonetos ha llevado a cabo James Whiston en el mejor trabajo que conocemos acerca de ellos ${ }^{40}$.

Estas son las siglas empleadas en el aparato de variantes: Al (Alvar, 1975), A2 (Alvar, 1988), AA (Aurora de Albornoz, 1961), AD (Almanaque. Destino. 1944, 1943), AT (Albornoz-Torre, 1964), B (Bergamín, 1940), GacHisp (Gaceta Hispana, 1938), H (La Habana, 1964), L (Losada, 1943), LasEsp (Las Españas, 1947), M1 (Macrí, Lerici, 1961), M2 (Macrí, Espasa Calpe, 1988), $O$ (original autógrafo), Orb (Orbis, 1988), $P$ (Rodríguez Puértolas-Pérez Herrero, 1983), Pl (Pleamar, 1944), SEI (Servicio Español de Información, 1938), V (Valencia a Machado, 1984). Aunque todas las ediciones sean descriptae del Servicio Español de Información y Hora de España, nos ha parecido ilustrativo para la historia interna de los textos dejar constancia de las variantes que introducen.

\section{COPLAS}

Se conservan en el ms. 22.233/1 de la Biblioteca Nacional de Madrid ${ }^{41}$. ¿Son los «versos prometidos» a que se refiere una carta de Machado a Juan José Domenchina fechada en Rocafort el 11 de febrero de $1938 ?^{42}$ Por

40 James Whiston, «"Más fuerte que la guerra": The Civil-war Sonnets of Antonio Machado», The Modern Language Review, vol. 88, part. 3 (July 1993), pp. 644-665.

${ }^{41}$ Dos cuartillas de 21'5 × 15'3 cms., autógrafas por una cara; la última, rubricada. Papel grueso, con marcas de agua. Cada uno de los dos poemas aparece en distinto folio. Texto impecable, como pasado a limpio; solo en el f. 2 se aprecia un ligero tachón. Sin fechar.

${ }^{42}$ Ms. 22.233/21 BNM. Aunque el segundo dígito de la fecha no es del todo claro, parece ser un 1 en el que se ha corrido la tinta, y no un 7 o un 3, con los que guarda 
eliminación de otras en que la alusión a poemas es más identificable, cabe la posibilidad de que así sea. Un argumento de orden interno, aunque no incontrovertible, sostiene esa conjetura: los vv. 18-19 de la primera composición, que dan las coordenadas espacio-temporales del poema si se les concede entidad real y no solo imaginaria:

Azotan el limonar

las ráfagas de febrero ${ }^{43}$.

Con todas las prevenciones, pensamos que el dato debe ser tenido en cuenta como hipótesis para la datación de los poemas, al menos hasta que aparezca algún ejemplar del primer suplemento literario del Servicio Español de Información o cualquier otro testimonio útil. Entre estos puede contarse un ensayo machadiano publicado por Hora de España justamente en febrero de 1938 que establece, como «Sobre la maleza», un contraste entre Shakespeare - con referencia a Macbeth-y Cervantes; cierto párrafo constituye un desarrollo de la parte central de ese poema que pone de manifiesto la analogía entre el artículo y los versos ${ }^{44}$.

alguna semejanza. Julio Rodríguez Puértolas y Gerardo Pérez Herrero no ponen esta carta en relación con las Coplas, y afirman de ella que «resulta poco menos que imposible saber a qué versos se refiere aquí Machado, sin duda publicados en el hoy inencontrable Suplemento Literario del Servicio Español de Información»(A. MACHADO, La guerra. Escritos: 1936-1939, ed. cit., p. 427).

${ }^{43}$ Los limoneros de «Villa Amparo», la residencia de Machado en Rocafort hasta abril de 1938, despertaron la vena lírica de alguno de sus visitantes: «En este Rocafort levantino moró Machado algunos meses. Ocupaba un bello chalet en la parte baja del pueblo, con un huerto de jazmines, de rosales y limoneros. [...] Allí, o a la sombra de aquellos limoneros cuajados de amarillos frutos, compuso seguramente el poeta sus últimas estrofas. [...] Los limoneros desgarraban sus ramas con la acongojada acidez de sus frutos» (Pascual Pla Y Beltrán, «Mi entrevista con Antonio Machado», de agosto de 1937, ap. Antonio Machado, II. Prosas completas. Edición crítica de Oreste Macrí con la colaboración de Gaetano Chiappini. Madrid: Espasa-Calpe / Fundación Antonio Machado, 1988, pp. 2.206-2.207).

44 "“QQué te parece desto, Sancho?, dijo Don Quijote: ¿hay encantos que valgan contra la verdadera valentía? Bien podrán los encantadores quitarme la ventura, pero el esfuerzo y el ánimo será imposible". En el capítulo más original del Quijote, así habla el Caballero de la Triste Figura, terminada su genial aventura de los leones. Claro se ve que es Don Quijote, nuestro Don Quijote, el verdadero antipolo del pragmatista, del hombre que hace del éxito, de la ventura, la vara con que se mide la virtud y la verdad. Es muy posible que un pueblo que tenga algo de Don Quijote no sea siempre lo que se llama un pueblo próspero. Que sea un pueblo inferior: he aquí lo que yo no concederé nunca. Tampoco hemos de creer que sea un pueblo inútil, de existencia superflua para el conjunto de la cultura humana, ni que carezca de una misión concreta que cumplir, o de un instrumento importante en que soplar dentro de la total orquesta de la historia. Porque algún día habrá que retar a los leones, con armas totalmente inadecuadas para luchar con ellos. Y hará falta un loco que intente la aventura. Un loco ejemplar» (A. MACHADO, «Miscelánea apócrifa. Habla Juan de Mairena a sus alumnos», Hora de España, XIV, febrero de 1938, p. 8). 
También los versos 8-11 de «Papagayo verde» — «Cuando truena el cielo / (¡qué bonito está / para la blasfemia!) / y hay humo en el mar...»— tienen un correlato en otro artículo de Machado más temprano que despeja cualquier duda sobre el sentido metafórico de ese trueno:

El Enemigo - los traidores de dentro y los invasores de fuera- se iba poco a poco aproximando a Madrid. La aviación enemiga multiplicaba sus asesinatos monstruosos de los inermes y de los inofensivos: de enfermos, de ancianos, de mujeres, de niños. El cielo otoñal madrileño, con sus nubes de plata y sus lluvias ligeras, tan alegre antaño, tan hospitalario y acogedor cuando nos anunciaba los días del renacer de la vida ciudadana, la vuelta de los escolares a sus estudios, la reapertura de sus centros de solaz y cultura, era ahora una constante invitación a la blasfemia, a una blasfemia que los combatientes no proferían $^{45}$.

Del corpus que estudiamos, son las coplas las más herméticas, en su concentración impresionista, pero textualmente las menos deturpadas. Las variantes generadas en la transmisión editorial son casi todas de puntuación, la mayoría atendibles, aunque alguna innecesaria, como la omisión general de la coma tras «altos» (v. 12 de «Papagayo verde»). En el v. 8 de esa composición hemos suprimido la coma del autógrafo tras «cielo» por encontrarse ante un paréntesis. Problema semejante lo hallamos un par de veces en «Sobre la maleza», con diferente solución en cada caso: la coma del v. 7 se pasa al final del 8 , y la del 12 se ha eliminado.

Las secciones de «Papagayo verde» han sido numeradas en romanos en Valencia a Machado, que - sin indicar la fuente- añade como colofón unos versos de Abel Martín clave acaso para dilucidar el enigmático comienzo del poema:

$$
\begin{aligned}
& \text { Y te daré mi canción, } \\
& \text { «se canta lo que se pierde», } \\
& \text { con un papagayo verde } \\
& \text { que la diga en tu balcón }{ }^{46} \text {. }
\end{aligned}
$$

«Sobre la maleza», a su vez, no aparece dividido en poemillas en $A A$, $A T, H, L, M 1, M 2, P, P l$ y $V$, sino solo en estrofas. La cita de Shakespeare (v. 5) es memorística ${ }^{47}$. En el v. 15, la intención primera del autor fue empezar por «bruñen», tachado. Domenchina glosó esa parte final en Las Españas:

45 A. MACHADO, «Madrid!», Servicio Español de Información, n. ${ }^{\circ} 279$ (7 de noviembre de 1937), p. 5.

${ }^{46}$ Valencia a Machado, ed. cit., p. 67. La cita procede, con la variante memorística transmitida por José Machado, de Juan de Mairena (ap. A. MaChado, IV. Prosas completas, ed. cit., p. 1.941).

47 «Thou shalt get kings, though thou be none / So all hail, Macbeth and Banquo» (Macbeth, I, 65-66). 
En el fondo de nuestra conciencia, como en los hondones del pensamiento del poeta desaparecido, se acusa, en contornos de pesadilla, y bajo un «sol que luce más allá del tiempo», la presencia de unos encantadores que bruñen, hasta convertirlos en radiantes oropeles, nuestros «mohosos harapos de hierro», que forjó la gloria y que oxidó la herrumbre de la locura ${ }^{48}$.

Testimonios: A1, A2, AA, AT, H, L, LasEsp, M1, M2, Orb, P, Pl, [SEI], $V$

\section{I}

Papagayo verde,

lorito real,

di tú lo que sabes

al sol que se va.

$$
\text { * * * }
$$

5

Tengo un olvido, Guiomar,

todo erizado de espinas,

hoja de nopal.

* * *

Cuando truena el cielo

(¡qué bonito está

10 para la blasfemia!)

y hay humo en el mar...

$$
\text { * * * }
$$

En los yermos altos, veo unos chopos de frío y un camino blanco.

$$
\text { * * * }
$$

15 En aquella piedra...

(¡tierras de la luna!)

¿nadie lo recuerda?

$$
\text { * * * }
$$

Azotan el limonar

las ráfagas de febrero.

No duermo por no soñar.

7 hoja] hojas $P \mathbf{8}$ cielo] , LasEsp, $O$ 11-12 sin partición en coplas $H 12$ altos,] coma om. $A 1, A 2, A A, A T, H, L, M 1, M 2, O r b, P, P l, V 15$ piedra...] puntos suspensivos om. A1, A2, L, Orb 16 tierras] tierra $L$

48 «Acto en recuerdo de don Antonio Machado», Las Españas, n. ${ }^{\circ} 4$ (29 de marzo de 1947), p. 15. «Nuestros peores enemigos han entrado todos por las puertas de la traición. Frente a ellos se yergue solitaria la hombría española, envuelta en los férreos harapos de nuestro Don Quijote, pero bañada en luz, toda vibrante de energía moral», había escrito Antonio Machado con imagen semejante a la de su poema, en octubre del 38 («Unas cuartillas de Machado», La Vanguardia, 29 de octubre de 1938, p. 1). 
Sobre la maleza, las brujas de Macbeth danzan en corro y gritan: ¡tú serás rey! (thou shalt be king, all [h]ail!)

$$
* \quad * \quad *
$$

Y en el ancho llano: «me quitarán la ventura —dice el viejo hidalgo-, me quitarán la ventura, no el corazón esforzado».

$$
* \quad * \quad *
$$

Con el sol que luce más allá del tiempo (¿quién ve la corona de Macbeth sangriento?)

los encantadores del buen caballero bruñen los mohosos harapos de hierro.

1 maleza,] coma om. A1, A2, LasEsp, Orb 4 om. signos de admiración LasEsp || tú] mayúscula $P 5$ thou] mayúscula $P \|$ shalt] shall $P, V \|[$ h]ail] ail LasEsp, $O \|$ el $v$. 5 se repite en $P \mathbf{6}$ llano:] dos puntos om. A1, A2, Orb 7 ventura] , LasEsp, O 8 hidalgo-,] coma om. L, LasEsp, O 9 ventura,] coma om. A1, A2, Orb 12 tiempo] , LasEsp, Orb 14 sangriento?)] ?), A1, A2, Orb 17 bruñen] bruñan LasEsp

\section{SONETOS ESCRITOS UNA NOCHE DE BOMBARDEO, EN ROCA- FORT (VALENCIA) MARZO DE 1938}

Ms. 22.233/3 $\mathrm{BNM}^{49}$. Han de ser los poemas a que alude otra carta de Machado a Domenchina, en este caso fechada el 26 de marzo de 1938, y escrita en un papel igual en calidad y dimensiones al que ocupan aquellos ${ }^{50}$.

49 Cuatro cuartillas autógrafas por una cara, numeradas del 1 al 4; la última, firmada. Papel amarillento, con barbas en el borde inferior y corte irregular (dimensiones aproximadas de $18 \times 15^{\prime} 3 \mathrm{cms}$; la núm. 4 es más pequeña, con longitud entre 16’8 y 17’2 cms.). En cada hoja aparece un soneto completo. La tinta se ha corrido en más de un sitio.

50 «Le envío esas composiciones para el Boletín. Ruégole vele V. por que no salgan demasiadas erratas. Ya sabe V. que los buenos cajistas, no solo se equivocan alguna vez, sino que corrigen, de cuando en cuando, las palabras que no entienden. En mis últimos versos publicados hay un gobernable, por gobernalle o gobernallo, que quita la cabeza. Aunque las erratas sean la salsa de los libros — como decía un cajista a nuestro amigo Juanito Ramón- en los versos convendría servirlas aparte» (A. MACHADO, ms. 22.233/24 BNM). Creemos que su fecha es, en efecto, el 26 de marzo, y no el 28, como también podría interpretarse. 
Si el parentesco que establecemos entre poemas y nota non cupatoria es correcto, la indicación temporal del epígrafe puede acotarse un poco más: los sonetos habrían sido concebidos en alguna de las noches previas al 26 de marzo, si no la misma velada del 26 o del 25, pues no creemos que en semejantes fechas de incertidumbre y necesidades tan imperiosas el autor demorara mucho la entrega de un escrito.

Asistimos en el primero de ellos, «La primavera», al triunfo de la naturaleza sobre la historia. Un Machado íntimo, mucho más au dessus de la mêlée que su persona pública, es capaz de percibir, con ese característico sentido suyo de la eternidad que tanto nos seduce, bajo el estruendo bélico el «rabel florido» de la Primavera invicta e inmortal ${ }^{51}$. (Más arriba — nota 5quedó constancia del gusto de Juan José Domenchina por ese último verso; no es aquella la única vez que lo recuerda en sus escritos). No presenta este soneto especiales dificultades textuales. Respetamos la puntuación del autógrafo, aunque no nos parece la óptima: como se observará, varios editores han suprimido la coma del v. 3 , no con mal criterio; más necesario en todo caso sería ponerla en el v. 1 para aislar la larga subordinada temporal (vv. 2-4), pues «fuerte» (v. 1) es predicativo subjetivo de un sujeto que no aparece hasta el v. 5, «tu alegre zalema»:

Más fuerte que la guerra —espanto y grima-,

cuando con torpe vuelo de avutarda

el ominoso trimotor se encima

y sobre el vano techo se retarda,

hoy tu alegre zalema el campo anima...

Puntuando así se atenuaría la complicación ocasionada por la prolepsis del predicativo y el largo inciso temporal (prueba de esa dificultad es la lectura simplificada - y disparatada - de Gaceta Hispana en v. 5, «su alegre zalema», con cambio de posesivo que convierte al sintagma en complemento directo y a «el campo» en sujeto de «anima», desbaratando sintaxis y sentido).

De puntuación es asimismo la principal variante del segundo soneto, «El poeta recuerda las tierras de Soria»: todos los testimonios se han apartado del autógrafo en el v. 5, aunque el cambio no altera el sentido; ninguno, por el contrario, ha rectificado la abrupta puntuación del sexto verso. En ese poema, al igual que en el anterior, también es un avión de combate el motivo desencadenante, que no se nos aparece hasta el terceto. $\mathrm{Su}$ rumbo hacia «el alto Duero» (v. 10) lo es hacia el propio pasado para el poeta de Campos de Castilla y «La tierra de Alvargonzález», reminis-

${ }^{51}$ No todos los estudiosos entienden que el vocativo del v. 13 «niña inmortal, infatigable dea» se dirija a la Primavera, como aquí sostenemos. Por ejemplo, A. Sánchez Barbudo $-\mathrm{y}$ a su zaga, B. Sesé- piensan que se trata de Leonor. 
cencias en las que se funda la hondura del poema. Algo parece fallar, sin embargo, en esos versos finales (no solo la entrecortada puntuación del 13): ¿por qué ha de haber oposición entre que Soria recuerde a Machado y que Caín domine el planeta?

Para Macrí, acaso despistado por el título, el tercero de la serie «evidentemente fue escrito en Valencia, donde residió el poeta hasta diciembre de $1937 \gg{ }^{52}$. Según eso, sería anterior a 1938, hipótesis que no solo pasa por alto la indicación incontrovertible del autógrafo (marzo de 1938), que Macrí conoce, sino que desatiende la precisión del propio primer verso —las «rachas de marzo»—, sembrando además la confusión con el empleo de un topónimo que puede designar tanto la ciudad como la provincia (del contexto se desprende que Macrí se refiere a la capital valenciana). Que el soneto fue escrito en Rocafort en marzo de 1938 es sin embargo indiscutible; no hay por qué poner en entredicho la palabra del autor. El título del poema - «(Desde una torre). Amanecer en Valencia»- no lo desdice, sino que lo corrobora: desde la torre de su palacete de Rocafort, Machado contempla en la distancia la salida del sol sobre Valencia. Cierto es que la posposición de la frase parentética en los impresos ha difuminado un tanto ese sentido. Un pasaje de los recuerdos de José Machado, fruto de vivencias compartidas con su hermano Antonio, ilumina probablemente la génesis de este soneto, y por extensión la de los otros tres de su ciclo:

En el amplio comedor se quedaba todas las noches ante su mesa de trabajo y como de costumbre rodeado de libros. Metido en su gabán desafiaba al frío escribiendo hasta las primeras horas del amanecer en que abría el gran ventanal para ver la salida del sol o, en otras ocasiones, y a pesar de estar cada día menos ágil, subía a lo alto de la torre para verlo despertar allá lejos, sobre el horizonte del mar.

En estas largas noches invernales trabajaba, trabajaba sin cesar para atender al sinfín de peticiones que de todas partes le hacían. Muchas veces tenía que apagar su luz ante los feroces bombardeos que irrumpían frenéticos sobre la hermosa ciudad del Guadalaviar. Momentos antes se había sentido sobre Rocafort el ruido de motores de los aviones que iban a volar sobre la indefensa ciudad. Después se veían rojas llamas que desgarraban el negro azul de la noche.

Apenas terminado el bombardeo sigue impertérrito el poeta su labor. Y así casi todas las noches, sin dejar de trabajar por nada ${ }^{53}$.

Responde solo parcialmente a los hechos, por tanto, la presunta confiden-

52 A. Machado, Poesías completas. Ed. de O. Macrí cit., pp. 1.010-1.011.

53 José Machado, Últimas soledades del poeta Antonio Machado. Recuerdos de su hermano José (Madrid: Ediciones de La Torre, 1999), p. 125. El mecanoscrito original, de 1940, conservado en la Biblioteca Nacional de Madrid (sig. R-63677), presenta alguna variante atenuadora («a perpetrar la cobarde hazaña sobre la indefensa ciudad» por «a volar sobre la indefensa ciudad», «el criminal bombardeo» por «el bombardeo», loc. cit., p. 93). 
cia de Antonio Machado a Max Aub: «Yo escribiré versos sobre Valencia. Cuando ya no esté aquí. Yo no puedo escribir nunca sobre lo que me rodea y sucede. Escribo con el recuerdo» ${ }^{54}$. Aunque no carece de verdad poética: los limoneros de Rocafort azotados por el viento de febrero, el trimotor nocturno, el sol que asoma, son lo que rodea y sucede al poeta mientras escribe. Pero constituyen tan solo el detonante de su inspiración: el verdadero asunto es otra realidad lejana — Guiomar, Soria o Valencia-, estilizada en el recuerdo.

Es este tercer soneto el más interesante desde el punto de vista textual. La mencionada inversión del título es común a todas las fuentes impresas. Todas ellas suprimen además la coma al final del v. 1 (nosotros también, por razones obvias). Pero la transmisión se bifurca en el v. 6, entre las que leen «valentina», como el autógrafo, y las que trivializan en «levantina» (entre ellas, la edición crítica, como vimos). El primer verso del poema hubo de servir de inspiración a Juan José Domenchina en 1944 al componer el soneto de Pasión de sombra «Son las rachas de marzo. Son el viento» ${ }^{55}$.

Si en contra de lo que afirma Machado existe una correspondencia entre el plano empírico y el creativo, «La muerte del niño herido», último soneto de la serie, no ha de serlo cronológicamente (el anterior se sitúa en el amanecer y este todavía en la noche cerrada). No es prudente aseverarlo. Tampoco que las mayúsculas por las que hemos optado en los versos 4 y 7 reflejen la voluntad del poeta, imposible de determinar en un autógrafo donde todos comienzan con versal.

Testimonios: A1, A2, AA, AD (sólo el n. ${ }^{\circ}$ III), AT, B, GacHisp, H, HdE, $L, M 1, M 2, O r b, P, P l, S E I, V$

\section{I \\ La primavera}

Más fuerte que la guerra —espanto y grimacuando con torpe vuelo de avutarda el ominoso trimotor se encima, y sobre el vano techo se retarda,

5 hoy tu alegre zalema el campo anima, tu claro verde el chopo en yemas guarda.

Fundida irá la nieve de la cima al hielo rojo de la tierra parda.

${ }^{54}$ M. AuB, «Antonio Machado en el décimo aniversario de su muerte», ap. Cuerpos presentes. Edición, introducción y notas de José-Carlos Mainer. Segorbe: Fundación «Max Aub», 2001, p. 169.

55 J. J. Domenchina, Pasión de sombra (Itinerario). México: Editorial Atlante, 1944, p. 44. 
Mientras retumba el monte, el mar humea,

10 da la sirena el lúgubre alarido, y en el azul el avión platea,

¡cuán agudo se filtra hasta mi oído, niña inmortal, infatigable dea, el agrio son de tu rabel florido!

3 encima,] coma om. A1, A2, AT, H, L, Orb, $P, P l, V 4$ retarda,] coma om. M1 6 tu] su GacHisp 8-9 sin sangrado interestrófico A1, Orb 10 da] de $V \|$ alarido,] coma om. $P, V$ 11-12 sin sangrado interestrófico A1, Orb 11 platea,] . AA

II

El poeta recuerda las tierras de Soria

¡Ya su perfil zancudo en el regato, en el azul el vuelo de ballesta, o, sobre el ancho nido de ginesta, en torre, torre y torre, el garabato de la cigüeña!..[.] En la memoria mía, tu recuerdo a traición ha florecido; y hoy comienza tu campo empedernido el sueño verde de la tierra fría,

Soria pura, entre montes de violeta.

10 Di tú, avión marcial, si el alto Duero a donde vas recuerda a su poeta,

al revivir su rojo Romancero; ¿o es, otra vez, Caín, sobre el planeta, bajo tus alas, moscardón guerrero?

1 ;Ya] admiración om. $V 2$ en] Y praem. (y tacha) $O \|$ vuelo] cielo A1, A2, Orb 4 torre, torre] torre, GacHisp 5 mía,] coma om. A1, A2, AA, AT, B, GacHisp, H, HdE, L, M1, M2, Orb, $P, P l, S E I, V 8$ fría,] . A1, A2, M2, Orb $\|$ verso omitido en $L \mathbf{9}$ violeta.] $\sim, L 11$ a donde] adonde $A 1, A 2, M 2$, Orb $\|$ vas] $\sim, A 1, A 2 \|$ poeta,] coma om. A1, A2, AT, H, L, Orb, P, Pl 12 Romancero;] : $L, P$

III

(Desde una torre). Amanecer en Valencia

Estas rachas de marzo, en los desvanes - hacia la mar- del tiempo; la paloma de pluma tornasol, los tulipanes gigantes del jardín, y el sol que asoma,

bola de fuego entre morada bruma, a iluminar la tierra valentina... ¡Hervor de leche y plata, añil y espuma, y velas blancas en la mar latina!

Valencia de fecundas primaveras, 
de floridas almunias y arrozales, feliz quiero cantarte, como eras,

domando a un ancho río en tus canales, al dios marino con tus albuferas, al centauro de amor con tus rosales.

Título: Posponen la frase parentética A1, A2, AA, AT, B, GacHisp, H, HdE, L, M1, M2, Orb, $P, P l, S E I, V$. En $A D$ el título es «Marzo» 1 desvanes] $\sim, O 5$ morada] dorada $A 1, A 2$, Orb 6 valentina $A 1, A 2, A D, G a c H i s p, H, H d E, L, O, O r b, P l, S E I]$ levantina $A A, A T, B, M 1, M 2, P, V$

\section{IV \\ La muerte del niño herido}

Otra vez en la noche... Es el martillo de la fiebre en las sienes bien vendadas del niño. - Madre, ¡el pájaro amarillo! ¡Las mariposas negras y moradas!

-Duerme, hijo mío. Y la manita oprime la madre, junto al lecho. - $;$ Oh, flor de fuego! ¿Quién ha de helarte, flor de sangre, dime? Hay en la pobre alcoba olor de espliego;

fuera, la oronda luna que blanquea cúpula y torre a la ciudad sombría. Invisible avión moscardonea.

- ¿Duermes, oh dulce flor de sangre mía?

El cristal del balcón repiquetea. - ¡Oh, fría, fría, fría, fría, fría!

1 en] es $A 1, A 2$, Orb 3 -Madre, (coma om. $A A, B, M 1, M 2)]$ —Madrid, $P, V 4$ Las] minúscula en AA, AT, B, GacHisp, H, HdE, L, MI, V 5 mío.] punto om. L, M1 - AA, B\|Y] — $A T, H, H d E, M 1, M 2, P, P l, V 6$ madre,] coma om. A1, $P \|$ lecho] - AT $\|-¡ \mathrm{O}$,] raya om. AT admiración om. GacHisp, SEI coma om. A1, A2, AA, AT, B, H, L, M1, M2, Orb, P, Pl 7 Quién] minúscula en AA, GacHisp, $H, H d E, L, M 1, M 2, P l, S E I, V 8$ Hay] minúscula en M1, M2 \| espliego;] : A1, Orb, $P 9$ fuera,] coma om. A1, $P, V \|$ blanquea] corr. sobre: platea $O \mathbf{1 2}$ dulce flor] dolceflor GacHisp

\section{LA GUERRA}

Son los cuatro poemas que constituyen el ms. 22.233/2 BNM $^{56}$. A ellos seguramente $-\mathrm{y}$ no a los cuatro anteriores, como piensan entre otros Julio Rodríguez Puértolas, Gerardo Pérez Herrero y James Whiston- se refiere una nueva carta del autor a Domenchina, por desgracia sin fecha ni lugar

${ }^{56}$ Cuatro cuartillas autógrafas por una cara $\left(18 \times 16^{\prime} 9 \mathrm{cms}\right.$.), numeradas del 1 al 4; la última, con rúbrica del poeta. El borde inferior de cada hoja tiene barbas, como si hubiera sido troceado de un pliego. Cada soneto ocupa una hoja; textos muy limpios, sin fechar. 
de procedencia que nos hubieran permitido localizar la composición de los sonetos:

Le envío esos cuatro sonetos de circunstancias, que quisieran estar a la altura de las circunstancias. Creo que dentro del molde barroco del soneto, contienen alguna emoción que no suelen tener los sonetos. De todos modos, en estos momentos de angustia en que la verdad se come al arte, no es fácil hacer otra $\cos \mathrm{a}^{57}$.

¿Es la serie La guerra anterior o posterior a los sonetos alumbrados durante la noche de bombardeo de finales de marzo? No lo sabemos: lo único seguro es que no guarda unidad con ellos. El resto son hipótesis. Puede que esté escrita en el mismo mes de marzo, como se suele creer, o puede que no. Personalmente, nos parece notar en ella un tono más imperioso, como también en la carta que la acompaña, que nos lleva a pensar que acaso sea más tardía. ¿Resulta quizá más emocionante por ser más próxima al desenlace de la guerra (y de la vida del ya por entonces enfermo Machado)? ¿Habrá sido compuesta todavía en Rocafort, o ya en Barcelona? ¿Tendrán que ver los «momentos de angustia» de la carta machadiana con la inminencia de su traslado forzoso a la ciudad condal? De ser así, los sonetos podrían fecharse todavía en Rocafort, en abril del 38 (en la primera quincena, si la fecha del traslado del poeta a Barcelona que apunta Bernard Sesé es correcta). Desde la torre vigía de su chalet, Machado veía el mar que canta en el primer soneto, como sabemos (y aunque también sabemos que presumía de escribir «con el recuerdo», la referencia espacial en ese poema es parte constitutiva). Pero mientras desconozcamos la fecha de aparición del suplemento del Servicio Español de Información donde salieron no podremos siquiera descartar que sean incluso más tardíos, y que estén escritos ya en Barcelona. No parece que el ambiente del Hotel Majestic donde primeramente se hospedó el poeta, según lo ha descrito su hermano José, fuera el más adecuado para el lirismo (o quizás sí, por reacción al medio). Su traslado a la Torre Castañer, un mes después de llegar a Barcelona, tal vez nos sitúe en fecha demasiado tardía, aunque en circunstancias más propicias al tipo de reflexión que se observa en los sonetos. En esa residencia disponía Machado de un jardín interior, y de un parque casi

${ }^{57}$ A. M., ms. 22.233/8 BNM. Se trata de una cuartilla con el mismo ancho que los autógrafos de «La guerra»; el largo no coincide, porque se ha cortado el borde inferior. Para la asignación de J. Rodríguez Puértolas y G. Pérez Herrero, cf. A. MACHAdO, La guerra. Escritos: 1936-1939, ed. cit., p. 428; para la de J. Whiston, cf. "“Más fuerte que la guerra": The Civil-war Sonnets of Antonio Machado», loc. cit., p. 644. Domenchina menciona esta epístola en el prólogo a El extrañado, con una apostilla curiosa, que no compartimos: "A Antonio Machado [el soneto] se le antoja —me lo dice así en una carta- un "molde barroco". Ninguno de los que escribió logra categoría de dechado» (J. J. Domenchina, El extrañado. México: Tezontle, 1958, p. 16). El criterio de un sonetista consumado como él merece atención. 
selvático. ¿Vería el mar también desde allí? Son conjeturas sobre conjeturas, en nuestro sentir menos firmes que la posibilidad (tampoco demostrada) de que los poemas no estén escritos en Barcelona, sino todavía en Rocafort, pero no en marzo, sino ya en abril de 1938, como antes sugerimos. La precisión puede parecer nimia, pero no lo es: en 1938 en España, una sola hora, un solo día — no digamos un mes-, cuentan mucho.

La profundidad de estos sonetos, como la de los cuatro anteriores, es más fácil de percibir que de explicar. Hay un ellos un espesor temporal, un poder de evocación, que impresionan y conmueven. El maestro de la reticencia que es Antonio Machado se supera aquí a sí mismo. ¿Cómo glosar lo que entraña un verso de factura tan simple y casi tópica como ese «Mi Sevilla infantil ¡tan sevillana!»? Sus resonancias son insondables. A muchos codos por encima de las desavenencias humanas, cabría decir que el Machado de 1938 escribe ya sub specie aeternitatis. No es un afán polémico el que instiga al poeta. Pero esa guerra que no ha conseguido agitar en él la musa de Tirteo tampoco va a acallar su voz, sino a darle un patetismo que podemos calificar de definitivo, atendiendo a las circunstancias.

El primero de los poemas, celebérrimo, presenta en la mayoría de los testimonios, a excepción del autógrafo, el Servicio Español de Información y la edición de Losada, una variante en el verso 5 que ya hemos mencionado: «otro mar» por «otra mar». El cambio de género procede de Hora de España, como vimos, y ha sido asumido sin vacilación por los editores. Es improbable que constituya una corrección de Machado en pruebas; no parece que se justifique, salvo por error, la intromisión del indefinido en masculino en una serie (vv. 2, 3, 5) donde «mar» es nombrado siempre en femenino, incluso en el mismo verso.

De los diez poemas que estudiamos, este es con razón el más recordado y comentado. Es posible que alguien haya reparado en la inexactitud histórica que subyace a su enorme eficacia poética: cuando Machado escribe el poema, Pilar de Valderrama, su destinataria, ya no se encontraba como aquel creía en Portugal, a donde, en efecto, se había dirigido con los suyos meses antes de comenzar la guerra civil española huyendo del desastre que se avecinaba. Tras una breve estancia en Lisboa, Guiomar se estableció en Estoril. Pero regresó a España en febrero de 1937, no a su domicilio madrileño, destruido en los primeros días del alzamiento, sino a Palencia, donde ella y su familia se albergaron en una casona de la plaza de San Pablo propiedad de su suegra ${ }^{58}$. Allí pasó buena parte de la guerra, y allí se hallaba para las fechas en que Machado compuso este soneto. Solo que desde su despedida antes de partir a Portugal había perdido la comunicación con el poeta, y por tanto Machado en 1938 la hacía aún en tierras

${ }^{58}$ Ella misma lo ha narrado en Sí, soy Guiomar. Memorias de mi vida (Barcelona: Plaza \& Janés, 1981), pp. 52-62. 
lusitanas. Tristemente para los protagonistas, pero afortunadamente para la poesía: el conocimiento de su verdadero destino hubiera impedido este soberbio soneto. La anécdota no da pie a convenir, con Aristóteles, en la superioridad moral de la poesía sobre la verdad histórica, pero sí revela la indudable ventaja artística de ciertas falsedades.

La propia Pilar de Valderrama es autora de una «Glosa» a este soneto, más sentida que inspirada ${ }^{59}$.

En el v. 3 de «Otra vez el ayer. Tras la persiana» casi todos los testimonios han empeorado la puntuación del autógrafo. Mantenemos la minúscula del v. 6, a pesar de que parece exigir una coma al final del verso anterior que no figura en el manuscrito. En «Trazó una odiosa mano, España mía», hemos trasladado la coma del v. 1 al final del dos. El v. 9 de esa composición presenta una triple irregularidad — la interjección en mayúscula en medio de una frase, la ausencia de coma ante el vocativo intercalado y la falta del signo final de admiración - que admite distintas soluciones:

Otra vez — ¡otra vez!-[,] ¡oh triste España[!],

Otra vez — ¡otra vez! — oh triste España,

o bien:

Otra vez —iotra vez!- ¡ ¡Oh triste España[!],

La primera nos ha parecido la más respetuosa con el texto.

La invocación directa a España del tercer soneto se convierte en el cuarto en apóstrofe con connotaciones bíblicas a la madre patria («varona» es el término con el que se designa a la madre primigenia, Eva, en el Génesis 2, 23). Ese soneto final constituye el reverso del anterior, y su superación en el plano ético: frente a la imprecación y el reproche, el afán de comprender y el perdón ${ }^{60}$. El símbolo de la traición - y de la redención- también es bíblico: Judas ${ }^{61}$. Nada gana la coherencia interna del concepto con el epígrafe «(A otro conde don Julián)» añadido al poema

59 «Me acompañó tu ausencia día a día» (P. DE VALDERRAMA, op. cit., pp. 97-98).

${ }^{60}$ Sobre esa generosidad moral de Antonio Machado es ilustrativo el testimonio de Pascual Pla y Beltrán: «Era un hombre tan bueno, que aun al mayor criminal le hubiera encontrado disculpa. Hubiera dicho: "Habrá que estudiar bajo qué circunstancias ha cometido tal acto. El hombre, que es un arcano temblor para la poesía, para la razón no puede ni debe ser un asombro. Investiguemos. La criatura humana es buena. En el fondo — ¿no te parece a ti, José? - todos tenemos algo noble, todos llevamos un poco de Dios en el corazón”» («Mi entrevista con Antonio Machado», loc. cit., p. 2.210).

61 Tampoco es la primera vez que el autor echa mano de él en el contexto de la guerra civil española: «Un político nefasto, un verdadero monstruo de vileza, mixto de Judas Iscariote y caballo de Troya, tomó a su cargo el vender —literalmente y a poco precio - a la República, al dar acogida en su vientre insondable a los peores enemigos del pueblo» (A. MACHADO, «El 14 de abril de 1937 en Valencia», ap. II. Prosas completas, ed. cit., p. 2.185). 
desde su aparición en Hora de España. Es verdad que tampoco tal referencia legendaria es ajena al repertorio machadiano ${ }^{62}$. Pero no creemos que un rótulo que destruye de ese modo la economía del poema pueda ser imputable al autor, sino más bien a un lector no demasiado atento, que ha proyectado en este el contenido del soneto previo (la carga política que la alusión al conde don Julián tenía en 1938 no desentona con la filiación ideológica de los redactores de Hora de España, ni sería la última vez en que un poema de guerra de Machado es tratado como bien mostrenco).

Testimonios: $A 1$ (sólo el soneto I), A2, AA, AT, B, H, HdE, L, M1, $M 2, P, P l, S E I, V$

De mar a mar entre los dos la guerra, más honda que la mar. En mi parterre, miro a la mar que el horizonte cierra. Tú asomada, Guiomar, a un finisterre, miras hacia otra mar, la mar de España que Camoens cantara, tenebrosa. Acaso a ti mi ausencia te acompaña. A mí me duele tu recuerdo, diosa.

La guerra dio al amor el tajo fuerte.

10 Y es la total angustia de la muerte, con la sombra infecunda de la llama

y la soñada miel de amor tardío, y la flor imposible de la rama que ha sentido del hacha el corte frío.

1 a mar] $\sim, A A, P, V \| \operatorname{dos}] \sim, P, V 4$ Tú (sin tilde en $O$ y en $A A, B, H d E, S E I)] \sim, A 1, A 2$, $A T, H, L, P, P l, V \mathbf{5}$ otra $(L, O, S E I)]$ otro $A 1, A 2, A A, A T, B, H, H d E, M 1, M 2, P, P l, V \mathbf{6}$ Camoens] , V 7 acompaña.] , B (aunque sigue mayúscula), M1, M2 8 mí] mi $A A 11$ la] tu $A 1$, $A 214$ ha] he $V$

\section{II}

Otra vez el ayer. Tras la persiana, música y sol; en el jardín cercano, la fruta de oro, al levantar la mano; el puro azul dormido en la fontana.

Mi Sevilla infantil ¡tan sevillana! ¡cuál muerde el tiempo tu memoria en vano!

62 «Ellos, en cambio, no han quemado todavía muchos palacios por motivos tan fútiles: los han dejado arder, los han expuesto al fuego de las bombas teutonas e italianas, para no ser infieles a los invasores de su patria. La única fidelidad de que pueden jactarse es la que tuvo el conde don Julián a sus propios rencores», afirma por boca de su heterónimo (A. MACHADO, «Mairena póstumo», ap. II. Prosas completas, ed. cit., pp. 2.400-2.401). 
¡Tan nuestra! Aviva tu recuerdo, hermano.

No sabemos de quién va a ser mañana.

10

Alguien vendió la piedra de los lares al pesado teutón, al hambre mora, y al ítalo las puertas de los mares.

[i]Odio y miedo a la estirpe redentora que muele el fruto de los olivares, y ayuna y labra, y siembra y canta y llora!

3 oro,] ; AA, AT, $P \|$ mano;] , A2, AA, AT, B, H, HdE, L, M1, M2, P, Pl, V 5 infantil] , $A 2, P, V \|$ sevillana!] $\sim$ !, $P, V \mathbf{6}$ cuál] sin tilde en $O$ y en $A A, P, V \|$ tu] corr. sobre: su $O \|$ vano!] $\sim: L \sim, P, V 7$ Tan] minúscula en $M 1, P, V \|$ Aviva] Avisa $A 2 \|$ hermano.] $\sim: P, V 8$ No] minúscula $P, V 11$ ítalo] sin tilde en $O$ y en $A A, B, H d E, S E I, V 12$;Odio] presentan signo de admiración AA, AT, B, H, Pl 14 siembra] corr. sobre: suda $O$

Trazó una odiosa mano, España mía - ancha lira, hacia el mar, entre dos mares-, zonas de guerra, crestas militares, en llano, loma, alcor y serranía.

Manes del odio y de la cobardía cortan la leña de tus encinares, pisan la baya de oro en tus lagares, muelen el grano que tu suelo cría.

Otra vez — ¡otra vez!-[,] ¡oh triste España[!], 10 cuanto se anega en viento y mar se baña juguete de traición, cuanto se encierra en los templos de Dios mancha el olvido, cuanto acrisola el seno de la tierra se ofrece a la ambición, jtodo vendido!

1 mía] , A2, AA, B, HdE, M1, M2, O, SEI, 2 mares-,] coma om. A2, AA, B, HdE, M1, M2, O, SEI 4 alcor] , M2 5 Manes] Manos V 9 Otra] — M2 \| vez!-,] coma om. todos los testimonios, incluido $O \|$ ¡oh (minúscula en todos los testimonios, excepto el autógrafo; y sin admiración $B, H, L, P l)] ~ ¡ O h O \|$ España!,] restituyen el signo de admiración en ese lugar $A 2, A A, B, M 1$, $M 210$ cuanto] cuánto $B, S E I$ cuando $L 11$ cuanto] cuánto $B, S E I 13$ cuanto] cuánto $B, S E I$

\section{II $[$ sic $]$}

Mas tú, varona fuerte, madre santa, sientes tuya la tierra en que se muere; en ella afincas la desnuda planta, y a tu Señor suplicas: ¡Miserere!

¿Adónde irá el felón con su falsía? ¿En qué rincón se esconderá, sombrío? Ten piedad del traidor. Parile un día, se engendró en el amor, es hijo mío. 
Hijo tuyo es también, Dios de bondades. Cúrale con amargas soledades. Haz que su infamia su castigo sea.

Que trepe a un alto pino en la alta cima, y en él ahorcado, que su crimen vea, y el horror de su crimen lo redima.

II $O$ ] IV SEI VIII resto de testimonios. Todos (AA, AT, B, H, HdE, M1, M2, Pl), excepto $O$ y SEI, anteponen al primer verso el encabezamiento "( $A$ otro conde D. Julián)», en A2 (como título), $A T, H, L$ y $P l$ sin paréntesis. 1 Mas] Más $A A, B 2$ muere;] , A2, AA, AT, B, H, HdE, L, $M 1, M 2, P, P l, V 5$ Adónde] A dónde $A T, L, P, V 6$ esconderá,] coma om. A2, AA, AT, B, M1, P, $V 13 \mathrm{y}] \sim, H, L, P l \|$ él] , AT, $P, V 14$ lo] le A2. Tras el último verso, añaden «Rocafort, marzo 1938» AA, AT, B, H, HdE, L, M1, M2, P, Pl, V «Rocafort, marzo de 1938» A2; frases ausentes en $O$ y SEI

Recuperamos, pues, para los futuros editores de la poesía machadiana una lectio difficilior - la «tierra valentina» de «Estas rachas de marzo, en los desvanes», v. 6-, relegada en la edición crítica; un género gramatical («De mar a mar entre los dos la guerra», v. 5); la fecha y circunstancias de composición de los sonetos «Más fuerte que la guerra - espanto y grima-», « $ү Y$ a su perfil zancudo en el regato...!», «Estas rachas de marzo, en los desvanes» y «Otra vez en la noche... Es el martillo»; la interdependencia de los dos dirigidos a España («Trazó una odiosa mano, España mía» y «Mas tú, varona fuerte, madre santa»), además de varias precisiones de puntuación. Todo ello con un grado considerablemente alto de fundamento. Ya en el terreno de las hipótesis, la autenticidad de la cabecera «(A otro conde D. Julián)» en el último soneto merece a nuestro juicio cautela. Proponemos los once primeros días de febrero de 1938 como margen probable de composición de las coplas «Papagayo verde» y «Sobre la maleza», y sugerimos reconsiderar la de los cuatro sonetos que forman la serie La guerra. Las últimas son solo conjeturas. Podemos, en cambio, tener la certeza de que estos poemas se cuentan entre lo mejor que dio la lírica española en aquellos años de infortunio. 